\title{
Study on Dynamic Properties of Alkali-activated Cementing Materials at Different Temperatures
}

\author{
Wujian Long ${ }^{1, a}$, Changle Fang ${ }^{1, b}$, Jingjie Wei $^{1, c}$ and Zhekang $\mathrm{Xu}^{1, \mathrm{~d}}$ \\ ${ }^{1}$ Guangdong Provincial Key Laboratory of Durability for Marine Civil Engineering \\ College of Civil Engineering, Shenzhen University, Shenzhen 518060, China. \\ alongwj@szu.edu.cn, ${ }^{b} 2150150420 @ e m a i l . s z u . e d u . c n,{ }^{c} 2150150416 @ e m a i l . s z u . e d u . c n,{ }^{d} 2014090$ \\ 204@email.szu.edu.cn
}

Keywords: alkali-activated cementing material, dynamic mechanic analyzer (DMA), temperature, loss factor, storage modulus.

\begin{abstract}
In this paper, variations of loss factor and storage modulus of Alkali-Activated Composite cementing materials (AAC) made from slag and fly ash and Ordinary Portland Cement (OPC) were studied at the temperature rising period from $40^{\circ} \mathrm{C}$ to $200^{\circ} \mathrm{C}$ by using Dynamic Mechanical Analyzer (DMA). The study showed that, compared to OPC, the dynamic properties of AAC were affected significantly by temperature and its loss factor increased gradually with the temperature, also, the variation of loss factor was larger than that of OPC. The storage modulus of both ACC and OPC was affected significantly by the temperatures and showed a similar change trend. With the temperature rising, the storage modulus reduced first and then tended to be stable. During the temperature rising, the flexural strength of AAC had a great loss.
\end{abstract}

\section{Introduction}

Data shows that $0.8 \mathrm{t} \mathrm{CO}_{2}$ is discharged for each ton of cement produced [1]. About $1.8 \mathrm{Gt}^{\mathrm{CO}_{2}}$ is discharged only from the cement industry in the world wide each year, accounting for 5-7\% [2] of total $\mathrm{CO}_{2}$ emissions by human production process. Studies showed that the cement industry is the third energy-consuming industry, just ranking after the aluminum making and iron making industries [3]. For each ton of cement produced, 1.5 tons of raw materials have to be consumed [4].

The alkali-activated concrete is produced by using alkali-activated cement to replace the conventional cementing materials [5-9]. In this way, $\mathrm{CO}_{2}$ discharge is largely reduced during the cement manufacture, also energy consumption is reduced and the industrial residues are reused properly, and the idea of going green and protecting the environment is embodied. Therefore, research and application of AAC are of great importance.

Neithalath has studied that the function of fiber of various types to the damping property of cement-based materials. However, small amount of fiber effected less on the loss factor of different cement-based materials [10]. Liu et al. have studied the improvement of nano-SiO 2 added to the concrete materials on the damping ability and it has got the maximum loss factor when the content of $\mathrm{SiO}_{2}$ is $4 \%$ [11]. Ke et al. have investigated the damping ratio, compressive strength and elasticity modulus of various kinds of concrete members, including ordinary concrete, light-weight aggregate concrete, rubber powder concrete, fly ash concrete, polymer concrete, polymer fly ash concrete [12]. In this paper, DMA was used to investigate the changing rule of loss factor and storage modulus at different temperatures of AAC materials.

\section{Materials and Methods}

\subsection{Raw Materials}

In this study, granulated blast furnace slag by Shunjie Minerals Co., Ltd was used, with density of $2.5 \mathrm{~g} / \mathrm{cm}^{3}$ (density strength Level S95). The chemical composition and relevant quality index of the slag are shown in Tables 1 and 2. Fly ash employed in this experimental was Class F Level I, and chemical composition is presented in Table 3. 
Table 1 Chemical compositions of slag (\%)

\begin{tabular}{cccccccccccccc}
\hline composition & $\mathrm{CaO}$ & $\mathrm{SiO}_{2}$ & $\mathrm{Al}_{2} \mathrm{O}_{3}$ & $\mathrm{MgO}^{2}$ & $\mathrm{SO}_{3}$ & $\mathrm{TiO}_{2}$ & $\mathrm{Fe}_{2} \mathrm{O}_{3}$ & $\mathrm{~K}_{2} \mathrm{O}$ & $\mathrm{MnO}$ & $\mathrm{Na}_{2} \mathrm{O}_{4}$ & $\mathrm{SrO}$ & $\mathrm{ZrO}_{2}$ & $\mathrm{Total}$ \\
\hline \multirow{2}{*}{ content } & 44.7 & 27.3 & 13.7 & 8.48 & 2 & 1.44 & 0.74 & 0.45 & 0.42 & 0.36 & 0.12 & 0.06 & 99.77 \\
\hline
\end{tabular}

Table 2 Quality index of slag

\begin{tabular}{cccc}
\hline Material & Alkaline coefficient & Activity coefficient & Quality coefficient \\
\hline Slag & 1.00 & 0.42 & 1.60 \\
\hline
\end{tabular}

Based on literature reviews and previous study [13-18], sodium silicate of modulus 1.95 was chosen in this study, with quality fraction of $\mathrm{Na}_{2} \mathrm{O}$ of $14.26 \%, \mathrm{SiO}_{2}$ of $26.92 \%$, and content of S, P or other insoluble matter lower than the limiting value.

Table 3 Chemical compositions of fly ash (\%)

\begin{tabular}{cccccccccccccc}
\hline Composition & $\mathrm{CaO}$ & $\mathrm{SiO}_{2}$ & $\mathrm{Al}_{2} \mathrm{O}_{3}$ & $\mathrm{MgO}$ & $\mathrm{SO}_{3}$ & $\mathrm{TiO}_{2}$ & $\mathrm{Fe}_{2} \mathrm{O}_{3}$ & $\mathrm{~K}_{2} \mathrm{O}$ & $\mathrm{MnO}$ & $\mathrm{Na}_{2} \mathrm{O}$ & $\mathrm{SrO}$ & $\mathrm{ZrO}_{2}$ & $\mathrm{Total}$ \\
\hline Content & 2.68 & 49.86 & 26.93 & 0.4 & 2.31 & 1.35 & 14.01 & 1.51 & 0.11 & 0.16 & 0.06 & 0.15 & 99.53 \\
\hline
\end{tabular}

Cement of Level P.II52.5 by China Resources was chosen in this study, with detailed characteristics shown in Table 4.

Table 4 Properties of cement

\begin{tabular}{|c|c|c|c|c|c|c|c|c|c|c|c|}
\hline \multirow{3}{*}{$\begin{array}{l}\text { Technical } \\
\text { index }\end{array}$} & \multicolumn{7}{|c|}{ Physical index } & \multicolumn{4}{|c|}{ Chemical index } \\
\hline & \multicolumn{2}{|c|}{ Setting time } & \multirow{2}{*}{$\begin{array}{c}\text { Specific } \\
\text { area } \\
\left(\mathrm{m}^{2} / \mathrm{kg}\right)\end{array}$} & \multicolumn{2}{|c|}{$\begin{array}{c}\text { Compressive } \\
\text { strength } \\
\text { (MPa) }\end{array}$} & \multicolumn{2}{|c|}{$\begin{array}{c}\text { Flexural } \\
\text { strength } \\
\text { (MPa) }\end{array}$} & \multirow{2}{*}{$\begin{array}{l}\mathrm{MgO} \\
(\%)\end{array}$} & \multirow{2}{*}{$\begin{array}{c}\mathrm{SO}^{2-}{ }_{4} \\
(\%)\end{array}$} & \multirow{2}{*}{$\begin{array}{l}\mathrm{Cl}^{-} \\
(\%)\end{array}$} & \multirow{2}{*}{$\begin{array}{l}\text { Ignition } \\
(\%)\end{array}$} \\
\hline & $\begin{array}{c}\text { Initial } \\
\text { setting(min) }\end{array}$ & $\begin{array}{l}\text { Final } \\
\text { setting } \\
\text { (h) }\end{array}$ & & 3d & 28d & $3 d$ & $28 \mathrm{~d}$ & & & & \\
\hline P.II52.5 & 126 & 2.9 & 346 & 30.1 & 60.8 & 6.6 & 9.0 & 1.06 & 2.47 & 0.01 & 2.5 \\
\hline
\end{tabular}

\subsection{Mix Proportion}

In the term of Water/Solid Ratio, Water means all water in the whole alkali-activated system (including water in activating agent and free water additionally added), and Solid means all solid materials which participate in the poly-condensation reaction, including cementing material to be activated (referring to slag and fly ash in this study) and solid alkali composition contained in activating agent solution (referring to $\mathrm{Na}_{2} \mathrm{O}, \mathrm{SiO}_{2}$ contained in sodium silicate in this study). In the term of Alkali/Binder Ratio, Alkali means the alkali composition contained in activator solution (referring to $\mathrm{Na}_{2} \mathrm{O}$ and $\mathrm{SiO}_{2}$ contained in sodium silicate in this study), and Binder means the raw materials of potential hydraulicity (referring to fly ash and slag in this study).

In ordinary Portland cement, water/cement ratio was chosen as 0.35 , with $0.1 \%$ water reducer added. Mix proportions of AAC is shown in Table 5.

Table 5 Mix proportions of AAC

\begin{tabular}{cccccc}
\hline Slag $(\mathrm{g} / \mathrm{L})$ & Fly ash $(\mathrm{g} / \mathrm{L})$ & sodium silicate $(\mathrm{g} / \mathrm{L})$ & Water $(\mathrm{g} / \mathrm{L})$ & Water/Solid & Alkali/Binder \\
\hline 600 & 66 & 378 & 72.6 & 0.32 & 0.24 \\
\hline
\end{tabular}

\subsection{Experimental Methods}

DMA instrument was used to determine the relationship of mechanical properties of viscous-elastic materials to time, temperature or frequency. When periodic (sinusoidal) mechanical stress applied on the sample, functional relationships of loss factor and storage modulus to the changing temperature were obtained, and dynamic properties changing of sample were reflected by these relationships. The size of the testing specimen was $100 \mathrm{~mm}$ length $\times 12 \mathrm{~mm}$ width $\times 5 \mathrm{~mm}$ height. After casted and molded, the testing pieces were sealed and cured for 24 hours at room temperature and then demoulded. Then placed in standard condition (with temperature of $20^{\circ} \mathrm{C} \pm 2^{\circ} \mathrm{C}$ and humidity more than 95\%) immediately and cured for 28 days. Flexural strength of the test pieces on Day 28 at room temperature $\left(28^{\circ} \mathrm{C}\right)$ and changing loss factor and storage modulus of the test specimen during the temperature rising were measured by DMA instrument. The static load applied on the test pieces were $1 \mathrm{~N}$, max. dynamic load was $0.5 \mathrm{~N}$, frequency was $0.1 \mathrm{~Hz}$, and the temperature changing range was $40^{\circ} \mathrm{C}$ to $200^{\circ} \mathrm{C}$ with rate of $10^{\circ} \mathrm{C} / \mathrm{min}$. 


\section{Experimental Results and Analysis}

Static flexural strength of AAC at ambient temperature $\left(28^{\circ} \mathrm{C}\right)$ on day 28 was $6.9 \mathrm{MPa}$, and static flexural strength of OPC was 6.5MPa.

\subsection{Loss Factor}

Variations of loss factors of AAC and OPC were shown in Figure 1 during the temperature rising on day 28.

The loss factor is also known as damping factor, internal friction or loss tangent, and is the ratio of dissipated energy to max. stored energy in one cycle. The size of loss factor represents the elastic property of material. The bigger value means the higher viscosity of material. Otherwise, means the higher elasticity of material.

It was shown in Figure 1 that the temperature affect less on the loss factor of OPC, but larger on that of AAC. The loss factor of AAC increased with the temperature rising. The experimental results also showed that the loss factor of AAC changed hardly during the temperature from $40^{\circ} \mathrm{C}$ to $85^{\circ} \mathrm{C}$, and retained about 0.075 . During the temperature rising from $85^{\circ} \mathrm{C}$ to $200^{\circ} \mathrm{C}$, the loss factor of AAC increased gradually, and reached 0.38 at $200^{\circ} \mathrm{C}$. The loss factor of OPC was affected less by the temperature and remained at about 0.03 during the temperature rising from $40^{\circ} \mathrm{C}$ to $70^{\circ} \mathrm{C}$. However, when the temperature was at $85^{\circ} \mathrm{C}$ and $170^{\circ} \mathrm{C}$, the loss factor of $\mathrm{OPC}$ appeared a peak and a trough, respectively with value of 0.10 and 0.02 . When the temperature increased to $200^{\circ} \mathrm{C}$, the loss factor increased to 0.10 . The reason for the rising of AAC loss factor may be that the bonds between gel molecule were destroyed with the temperature rising and some of energy was consumed. Deformation or breakage also might cause the loss factor going up during the temperature rising. Since AAC broke during the temperature rising, it could be deduced that large crack appeared in $\mathrm{AAC}$ at $85^{\circ} \mathrm{C}$. Friction and energy consumption happened between hydration products, causing AAC broken finally with the development and increase of cracks, which showed that the loss factor kept on increasing in the experiment.

\subsection{Storage Modulus}

Figure 2 showed the variations of storage modulus of AAC and OPC during the temperature rising at 28 days.

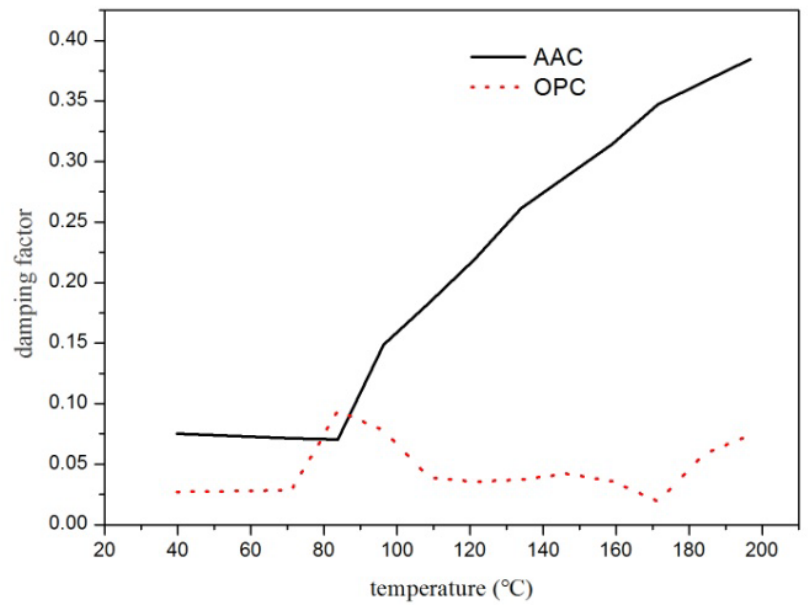

Figure. 1 Variations of loss factors of AAC and OPC during the temperature rising at 28 days

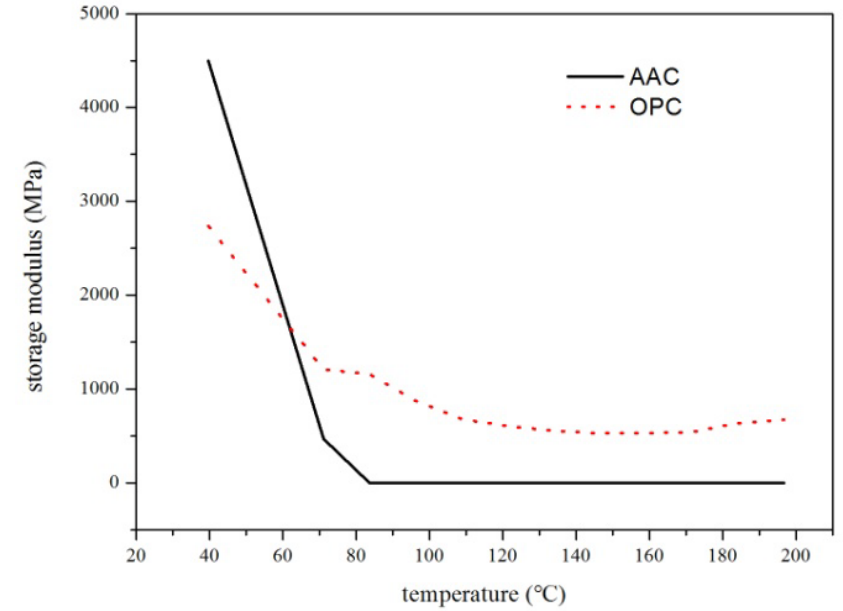

Figure. 2 Variations of storage modulus of AAC and OPC during the temperature rising at 28 days

Essentially, the storage modulus is Young modulus, indicating that the material's storage modulus is proportional to max. elasticity stored in each cycle when it is applied by alternating sinusoidal stress of variable amplitude. The storage modulus is the part of elasticity in viscoelasticity of the reaction materials, which represents the rigidity of material, and is the spring back index after the material deformed.

As shown in Figure 2, the storage modulus of the both materials reduced with the temperature rising during certain range. During the range of $40^{\circ} \mathrm{C}-85^{\circ} \mathrm{C}$, the storage modulus of both AAC and OPC reduced a lot. With the temperature continually rising, the storage modulus of AAC changed 
little, and $\mathrm{OPC}$ tended to be stable after $110^{\circ} \mathrm{C}$. The reason that the storage modulus of AAC and $\mathrm{OPC}$ reduced in the range of $40^{\circ} \mathrm{C}$ to $85^{\circ} \mathrm{C}$ might be that the elasticity composition reduced with the temperature rising, or cross linking degree of hydration products reduced with the temperature rising. When the temperature was above $85^{\circ} \mathrm{C}$, large crack appeared in AAC, and the material stayed in plastic state, causing its storage modulus low. Reason for the storage modulus of AAC and OPC relatively large might be that in the development tendency of cracks in OPC, its quantity increased but its width was small, causing the material not enter the plastic state. By combining the compressive strength of materials at room temperature and the breakage of AAC during the experiment, we can find that the strength of AAC loss a lot during the temperature rising up to $200^{\circ} \mathrm{C}$; However, no breakage happened to OPC during the whole temperature rising, and the strength loss is lower than AAC. AAC became very weak with its strength almost lost at high temperature. It indicates that AAC has poor ability to resist high temperature.

\section{Conclusions}

1) Compared to OPC, AAC is affected significantly by the temperature, and its loss factor increases gradually with the temperature rising. The changing amplitude of AAC loss factor is larger than that of OPC;

2) Storage modulus of both AAC and OPC was affected significantly by the temperature. They had similar changing trend and reduced first and then trend to be stable with the temperature rising;

3) AAC's flexural strength lost a lot during the temperature rising. It has worse ability to resist high temperature than OPC.

\section{Acknowledgments}

The authors gratefully acknowledge the financial support provided by the National Natural Science Foundation of China (No.51578341 and No.51278306), the Science Industry Trade and Information Technology Commission of Shenzhen Municipality (No. JCYJ20140418095735540).

\section{References}

[1] D.J. Flower, J.Y. San, Green house gas emissions due to concrete manufacture, Int J Life Cycle Assess. 12 (2007) 282-288.

[2] T.M. Gao, L. Shen, M. Shen, et al, Analysis on differences of carbon dioxide emission from cement production and their major determinants, J Clean Prod.103 (2014) 160-170.

[3] A.M. Rashad, A comprehensive overview about the influence of different admixtures and additives on the properties of alkali-activated fly ash, Mater Design. 53 (2014) 1005-1025.

[4] A.M. Rashad, An exploratory study on HVFA (high-volume fly ash) concrete incorporating silica fume subjected to thermal loads, J Clean Prod. 87 (2015) 735-744.

[5] T. Phoo-ngernkham, V. Seta, et al, Properties of high calcium fly ash geopolymer pastes with Portland cement as an additive, Int J Min Met Mater. 20 (2013) 214-220.

[6] L. Tang, H.E. Zhang, et al, Research on resistance to sulfates of fly ash based geopolymeric recycled concrete, J Sichuan Univ: Eng Sci Ed. 47 (2015) 164-170.

[7] Y.W. Fu, L.C. Cai, et al, Manufacturing process and properties of alkali-slag mineral polymer concrete, J Build Mater. 4 (2010) 524-528.

[8] M.R. North, T.W. Swaddle, Kinetics of silicate exchange in alkaline aluminosilicate solutions, Int Chem. 39 (2000) 2661-2665. 
[9] W.B. Liu, X.J. Xiao, Research process on alkali-activated binders, Ready Mix Concr. 9 (2010) 23-26.

[10] N. Neithalath, J. Weiss, J. Olek, Acoustic performance and damping behavior of cellulose-cement composites, Cem. Concr. Compos. 4 (2004) 359-370.

[11] T.J. Liu, G.F. Qiao, D.J. Zou, Improving the damping ability by the addition of nano-SiO ${ }_{2}$ to the concrete materials, J Funct Mater. 7 (2011) 1184-1189.

[12] G.J. Ke, C.Q. Guo, Z.F. Chen, Study on the damping ratio of concrete, J Build Mater. 1 (2004) 35-40.

[13] L. Diaz, Mechanical properties of fly ash based geopolymer concrete, ACI Mater. J. 108 (2011) 300-306.

[14] W.L. Peng, Study on the main properties of alkali activated recycled concrete and the design of mix ratio, Professional degree, Shenzhen Univ, China, (2016)

[15] L. Diaz, Factors affecting the suitability of fly ash as source material for geopolymers, Fuel.89 (2010) 992-996.

[16] M.T. Junaid, Reducing bleeding in mix for bored pile application without affecting other fresh concrete properties: methodology and procedure, EASEC-10, Bangkok, Thailand. 44 (2006) 74-75.

[17] B.V. Rangan, Concrete construction engineering handbook, CRC Press, New York, 2007.

[18] Y. Song, Study on the effect of surfactants on alkali slag system . Chongqing: Chongqing Univ. 2009, 41-42. 